\title{
The role of thrombophilic risk factors in the severity of pulmonary thromboembolism
}

\author{
I.K. Oguzulgen*, N.N. Ekim*, N. Akar", K. Demirel", M. Kitapci"
}

The role of thrombophilic risk factors in the severity of pulmonary thromboembolism. I.K. Oguzulgen, N.N. Ekim, N. Akar, K. Demirel, M. Kitapci. (C) ERS Journals Ltd 2002. ABSTRACT: High plasma factor-VIIIc concentration, presence of factor-V $1691 \mathrm{G}-\mathrm{A}$ (FVL) and prothrombin ${ }^{20210 \mathrm{~A}}\left(\mathrm{PT}^{20210 \mathrm{~A}}\right)$ mutations were shown to be significant risk factors for venous thromboembolism (VTE) and recurrent VTE. The objective of this study was to investigate the role of these thrombotic risk factors in the severity of pulmonary thromboembolism (PTE).

The plasma concentrations of factor VIIIc, presence of FVL and PT $^{20210 \mathrm{~A}}$ mutations were studied in 32 patients with PTE. Eleven of the patients had documented recurrent VTE. Lung perfusion scans were scored according to the percentage of vascular obstruction. Patients who had a pulmonary vascular obstruction score (PVOs) $>\mathbf{5 0} \%$ were compared to those with $\mathbf{P V O s}<\mathbf{5 0} \%$.

There was no significant difference between the patients with PVOs $>50 \%$ and those with PVOs $<50 \%$, with regard to the presence of $F V L$ and $\mathrm{PT}^{20210 A}$ mutation. However, patients with PVOs $>\mathbf{5 0} \%$ had a significantly higher factor-VIIIc concentration than those with PVOs $<\mathbf{5 0} \%$ (factor-VIIIc levels were $\mathbf{2 5 3 . 3} \pm \mathbf{2 9 . 1}$ International Units (IU) $\cdot \mathrm{dL}^{-1}$ and $138.5 \pm 16.2 \mathrm{IU} \cdot \mathrm{dL}^{-1}$, respectively; $\left.\mathrm{p}<0.005\right)$. Factor-VIIIc concentrations were significantly correlated with $\mathrm{PVOs}(\mathrm{r}=0.52, \mathrm{p}<\mathbf{0 . 0 0 5})$. Patients with recurrent VTE had significantly higher factor-VIIIc concentrations than those in which it occurred for the first time (factor-VIIIc concentrations were $232.6 \pm 30.9 \mathrm{IU} \cdot \mathrm{dL}^{-1}$ and $158.3 \pm 20.6 \mathrm{IU} \cdot \mathrm{dL}^{-1}$, respectively; $p<0.05$ ).

The authors conclude that in addition to being a risk factor for venous thromboembolism, high factor-VIIIc concentration is an important factor in the severity of pulmonary thromboembolism.

Eur Respir J 2002; 19: 709-711.

Venous thromboembolism (VTE) is a major health problem throughout the world. The annual incidence of VTE in the general population of the Western world is estimated to be $0.1-0.05 \%$ [1]. There are many well-known secondary risk factors responsible for VTE. Primary risk factors, known as congenital thrombophilic risk factors, should be seriously considered in patients who have had a documented unexplained thrombotic episode. The most commonly reported congenital risk factors are the factor-V 1691 $\mathrm{G}-\mathrm{A}$ (FVL) mutation, prothrombin ${ }^{20210 \mathrm{~A}}\left(\mathrm{PT}^{20210 \mathrm{~A}}\right)$ mutation, protein- $\mathrm{C}$ and $-\mathrm{S}$ deficiency and antithrombin deficiency [2, 3]. Recently, a high factor-VIIIc concentration was shown to be an independent and dose-dependant risk factor for VTE and recurrent VTE $[4,5]$. In this study, the authors aimed to investigate the role of some of the congenital thrombophilic risk factors (FVL, $\mathrm{PT}^{20210 \mathrm{~A}}$ mutation and high factor-VIIIc concentration) in the severity of pulmonary thromboembolism (PTE).

\section{Materials and methods}

\section{Study subjects}

The authors investigated 32 patients, 13 males and 19 females, aged $57.4 \pm 13.8 \mathrm{yrs}$, with documented
*Dept of Pulmonary Medicine, Gazi University School of Medicine, \#Dept of Paediatric Molecular Genetics, Ankara University School of Medicine, and Dept of Nuclear Medicine, Gazi University School of Medicine, Ankara, Turkey.

Correspondence: I.K. Oguzulgen

Turan Gunes Bulvari 92/2

Cankaya

Ankara

Turkey

Fax: 903122129019

E-mail: ipek@gazi.edu.tr

Keywords: Factor V

factor VIII

prothrombin

pulmonary embolism

Received: August 282001

Accepted after revision December 10 2001
PTE, confirmed by high-probability ventilation/perfusion lung scanning. Eleven of them $(34.4 \%)$ were identified as having documented recurrent VTE from the hospital records (one patient with recurrent PTE and 10 with recurrent deep venous thrombosis (DVT)). Twenty-three of the patients presented with isolated PTE, nine of which had PTE associated with DVT. Of the 32 patients studied, seven had no specific risk factor for PTE. In the remaining 25 patients: most had more than one risk factor; 15 had immobility; nine had DVT; nine had obesity; one had oestrogencompound usage; and two had multiple trauma. None had malignancies and familial history of PTE or DVT.

After diagnosis of PTE, blood samples were collected for laboratory studies. Twenty-six patients received anticoagulation therapy with standard heparin, followed by warfarin. The remaining six patients had clinically massive PTE and received thrombolitic therapy with recombinant tissue plasminogen activator (rt-pA), followed by the same anticoagulation therapy. Written informed consent was obtained from each patient.

\section{Study design}

In this prospective study, perfusion lung scans were used to assess the severity of the PTE. 
Scintigraphically-detectable pulmonary vascular obstruction was scored (PVOs) and patients with PVOs $>50 \%$ were compared to those with PVOs $<50 \%$, with respect to the presence of FVL, $\mathrm{PT}^{20210 \mathrm{~A}}$ mutations and high factor-VIIIc concentration.

\section{Assessment of pulmonary vascular obstruction}

To assess the severity of the PTE, scintigraphicallydetectable PVOs were independently expressed as a percentage by two nuclear medicine specialists, unaware of the clinical condition of the patient at the time of diagnosis. The method used to calculate this percentage has been described previously by MEYER et al. [6]. Each lobe was assigned a weight based on the regional distribution of pulmonary blood flow in the supine position: right lower lobe $25 \%$, right middle lobe $12 \%$, right upper lobe $18 \%$, left lower lobe $20 \%$, lingual $12 \%$, and left upper lobe $13 \%$. Perfusion within each lobe was estimated from the anterior, posterior and oblique views. For each lobe, a semiquantitative perfusion score, from $0-1(0,0.25,0.5$, 0.75 and 1), was estimated from the film density by comparison with the photodensity of an apparently normal perfused area. Each lobar-perfusion score was then calculated by multiplying the weight by the perfusion score. The overall perfusion score was determined by summing the six separate lobar-perfusion scores. The percentage of vascular obstruction by perfusion scanning (PVOs) was then calculated as:

PVOs $(\%)=(1-$ overall perfusion score $) \times 100$

There was a minimal intra-observer variability of PVOs analysis. The mean absolute difference of PVOs estimates was $2.8 \pm 2.1 \%$. The correlation between both lung-scan interpreters was very good, with a correlation coefficient of 0.91 and a mean absolute difference of $5 \pm 3.6 \%$ for the PVOs estimates. Patients with PVOs $>50 \%$ were compared to those with PVOs $<50 \%$.

\section{Laboratory studies}

Blood samples were collected from all patients at the time of diagnosis, before the onset of anticoagulation therapy. Deoxyribonucleic acid (DNA) was extracted by conventional techniques. The guanine (G)-to-adenine (A) transition at nucleotide 1691 within the factor-V gene and the G-to-A transition at nucleotide-position 20210 within the prothrombin gene locus were analysed according to previously reported techniques [7, 8]. Plasma factorVIII concentration was measured by a one-stage clotting assay with factor-VIII deficient plasma (Sigma Diagnostics, St. Louis, MO, USA).

\section{Statistics}

Differences in the proportions were analysed by the Chi-squared test. Differences in means were evaluated by the Mann-Whitney U-test. Correlation between PVOs and factor-VIIIc levels was analysed by a
Pearson correlation test. A potential continuous relationship was evaluated between the severity of PTE and risk factors using a logistic regression analysis.

\section{Results}

Mean \pm SEM (range) PVOs were $51.9 \pm 17.7 \%$ (23.2$82.5 \%$ ) in the whole study population. A total of 17 patients had PVOs $<50 \%(36.8 \pm 6.0 \%)$ and 15 had PVOs $>50 \%(69.1 \pm 7.7 \%)$. FVL and $\mathrm{PT}^{20210 \mathrm{~A}}$ mutations were present in six $(18.8 \%)$ and two patients $(6.3 \%)$, respectively. Seventeen patients $(53.1 \%)$ had a high factor-VIIIc concentration (252.3 \pm 23 Internatioal Units $(\mathrm{IU}) \cdot \mathrm{dL}^{-1}$; normal concentrations: 50-150 IU $\left.\cdot \mathrm{dL}^{-1}\right)$. There was no significant difference between the patients with PVOs $>50 \%$ and those with PVOs $<50 \%$ with respect to the presence of FVL $(20 \%(n=3)$ and $17.6 \%(n=3)$ in patients with PVOs $>50 \%$ and $<50 \%$, respectively) and the presence of $\mathrm{PT}^{20210 \mathrm{~A}}$ mutation $(6.7 \%(\mathrm{n}=1)$ and $5.9 \%(\mathrm{n}=1)$ in patients with PVOs $>50 \%$ and $<50 \%$, respectively). However, patients with PVOs $>50 \%$ had significantly higher factor-VIIIc concentrations compared to those with PVOs $<50 \%$ (factor-VIIIc concentrations were $253.3 \pm 29.1 \mathrm{IU} \cdot \mathrm{dL}^{-1}$ and $138.5 \pm 16.2 \mathrm{IU} \cdot \mathrm{dL}^{-1}$, respectively; $\mathrm{p}<0.005$ ) (fig. 1 ).

High factor-VIIIc concentration $\left(>150 \mathrm{IU} \cdot \mathrm{dL}^{-1}\right)$ was demonstrated in $80 \%$ of patients with PVOs $>50 \%$ and $29 \%$ of those with PVOs $<50 \%$ (odds ratio (OR): 9.6; 95\% confidence interval (CI): 1.8-49.4). There was a significant correlation between the factorVIIIc concentration and PVOs in the whole study population $(\mathrm{r}=0.55, \mathrm{p}<0.005)$ (fig. 2). Patients with recurrent VTE had significantly higher factor-VIIIc concentrations than those in which it occurred for the first time (factor-VIIIc concentrations were $232.6 \pm 30.9 \mathrm{IU} \cdot \mathrm{dL}^{-1}$ and $158.3 \pm 20.6 \mathrm{IU} \cdot \mathrm{dL}^{-1}$, respectively; $\mathrm{p}<0.05$ ).

In the logistic regression analysis, high factor-VIIIc concentration $\left(>150 \mathrm{IU} \cdot \mathrm{dL}^{-1}\right)$ was found to be the only significant $(\mathrm{p}<0.01)$ risk factor that predisposes to more severe thromboembolic disease (PVOs $>50 \%$ ).

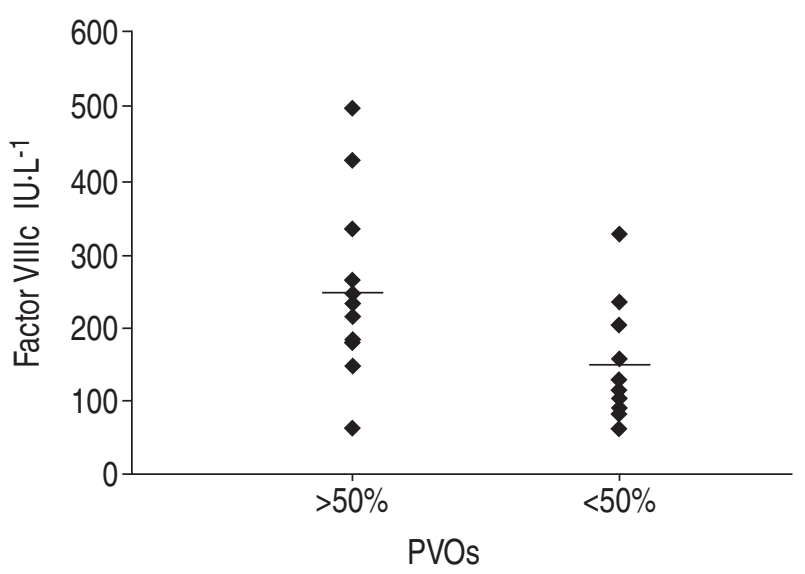

Fig. 1.-Factor-VIIIc levels in patients with pulmonary vascular obstruction scores (PVOs) $>50 \%$ and $<50 \%$. The small horizontal lines indicate the mean values. $\mathrm{p}<0.005$. IU: International Units. 


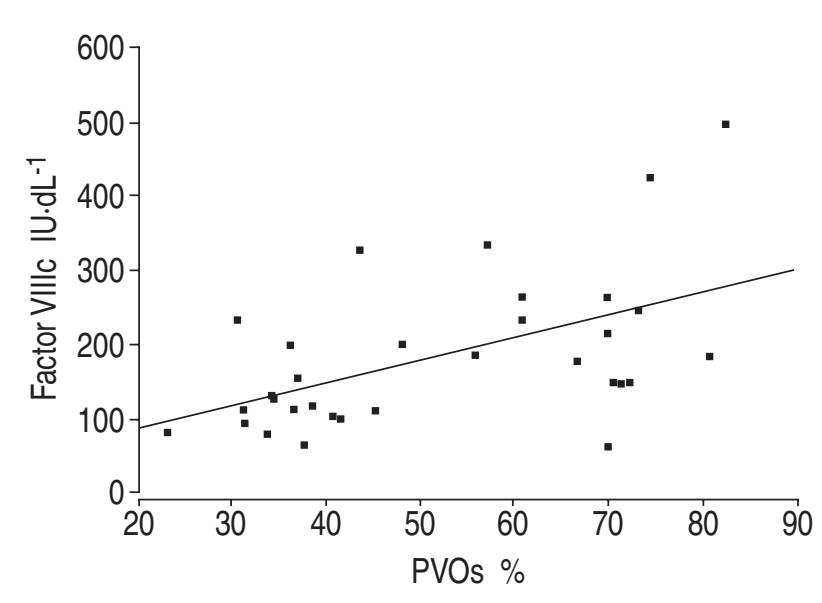

Fig. 2.-Correlation between the factor-VIIIc levels and the pulmonary vascular obstruction score (PVOs). $\mathrm{r}=0.55, \mathrm{p}<0.005$. IU: International Units.

\section{Discussion}

The present, prospective study showed that a high plasma factor-VIIIc concentration is a strong risk factor for severe PTE, with a significant correlation between the factor-VIIIc concentration and the degree of pulmonary vascular obstruction. Further, among the other thrombophilic risk factors studied, only high plasma factor-VIIIc concentration was associated with the severity of PTE.

Factor VIIIc was found to be a significant, prevalent, independent and dose-dependent risk factor for VTE in patients with DVT and PTE [4]. A study by KraAiJenhagen et al. [4] also showed that high concentrations of factor VIIIc persisted over time and that its role in DVT is not as an acute phase protein. High plasma concentration of factor VIIIc was also found to be associated with recurrent VTE [4]. The results were similar to the findings of KYRLE et al. [5], as in the present study group, patients with recurrent VTE had significantly higher concentrations of factor VIIIc than those in which it occurred for the first time.

The roles of FVL and $\mathrm{PT}^{20210 \mathrm{~A}}$ mutations were also investigated for VTE. Both mutations were found to be relevant risk factors for VTE, particularly for DVT and partly for isolated PTE [2, 3, 9]. However, neither high concentrations of factor VIIIc nor mutations in factor V Leiden and factor IIA 20210 were investigated for the severity of PTE.

In this study, PVOs were used to assess the severity of PTE, which was found to be a reliable method of assessing the per cent of pulmonary vascular obstruction [6]. It was found that patients with PVOs $>50 \%$ had significantly higher concentrations of factor VIIIc. It was also shown that patients with high factor-VIIIc concentrations $\left(>150 \mathrm{IU} \cdot \mathrm{L}^{-1}\right)$ had an increased risk of experiencing severe PTE (PVOs $>50 \%$ ) (OR: 9.6; 95\% CI: 1.8-49.4).

In the present study group, the prevalence of the FVL and $\mathrm{PT}^{20210 \mathrm{~A}}$ mutations was $18.8 \%$ and $6.3 \%$, respectively, which are higher than the reported frequencies of healthy Turkish adults $(10 \%$ and $2.6 \%$, respectively) $[7,8]$. The data on PTE patients were similar to those of previous reports [2, 3], but was not associated with the severity of PTE. However, in the present study population, the prevalence of an elevated plasma factor-VIIIc concentration was $53.1 \%$ higher than those reported in a previous study, which were $\sim 19 \%$ in patients with a single episode, $33 \%$ in patients with recurrent disease and $25 \%$ in the general VTE group [4]. This discrepancy may be explained by differences in the population of patients selected. All the patients in the group had PTE (23 had isolated PTE and nine had PTE associated with DVT), whereas the other studies contained mostly isolated DVT patients.

A possible limitation of the present study may be the small study population. If extended studies can confirm the present results, care must be taken with the patients with high factor-VIIIc concentrations, as they may not only experience recurrent but also severe VTE. To date, there is no consensus about the duration of oral anticoagulant therapy in patients with high factor-VIIIc concentrations. The authors believe that because a high factor-VIIIc concentration has a distinct role in the recurrence of VTE and the severity of PTE, prolonged anticoagulation must be taken into consideration.

\section{References}

1. Task Force on Pulmonary Embolism, European Society of Cardiology. Guidelines on diagnosis and management of acute pulmonary embolism. Eur Heart $J$ 2000; 21: 1301-1336.

2. Margaglione $\mathrm{M}$, Brancaccio $\mathrm{V}$, De Lucia $\mathrm{D}$, et al. Inherited thrombophilic risk factors and venous thromboembolism. Chest 2000; 118: 1405-1411.

3. Ordonez AJG, Carreira JMF, Alvarez CRF, Rodriguez JMM, Alvarez MV, Coto E. Comparison of the risk of pulmonary embolism and deep vein thrombosis in the presence of factor $\mathrm{V}$ Leiden or prothrombin G20210A. Thromb Haemost 2000; 83: 352-354.

4. Kraaijenhagen RA, Anker PS, Koopman MMW, et al. High plasma concentration of factor VIIIc is a major risk factor for venous thromboembolism? Thromb Haemost 2000; 83: 5-9.

5. Kyrle PA, Minar E, Hirschl M, et al. High plasma levels of factor VIII and the risk of recurrent venous thromboembolism. $N$ Engl J Med 2000; 343: 457-462.

6. Meyer G, Collignon MA, Guinet F, Jeffrey AA, Barritault L, Sors H. Comparison of perfusion lung scanning and angiography in the estimation of vascular obstruction in acute pulmonary embolism. Eur J Nuc Med 1990; 17: 315-319.

7. Akar N, Akar E, Akcay R, Avcu F, Yalcin A, Cin S. Effect of MTHFR 677 c-T, 1298 A-C and 1317 T-C on Factor V 1691 mutation in Turkish DVT patients. Tromb Res 2000; 97: 163-167.

8. Akar N, Misirlioglu M, Akar E, Avcu F, Yalcin A, Sozuoz A. Prothrombin gene 20210 G-A mutation in the Turkish population. Am J Hematol 1998; 58: 249.

9. Turkstra F, Karemaker R, Kuijer PM, Prins MH, Buller HR. Is the presence of the factor V Leiden mutation in patients with pulmonary embolism and deep vein thrombosis really different? Thromb Haemost 1999; 81: 345-348. 